Michael B. Hundley

\title{
Keeping Heaven on Earth
}

\section{Safeguarding the Divine Presence in the Priestly Tabernacle}

[Den Himmel auf Erden bewahren. Die Sicherung der göttlichen Gegenwart im priesterlichen Tabernakel.]

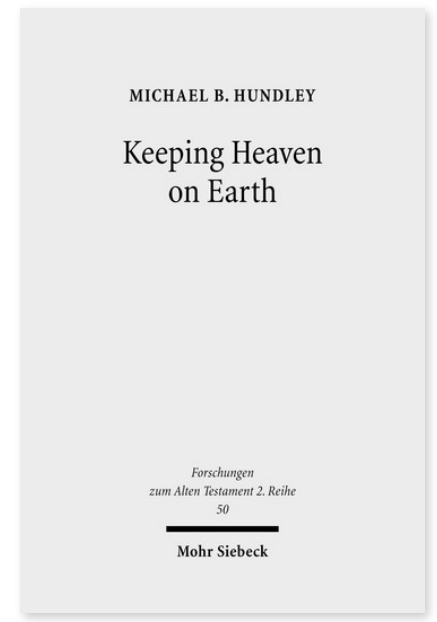

2011. XVI, 250 Seiten. FAT II 50

ISBN 978-3-16-151148-6

DOI 10.1628/978-3-16-151148-6

eBook PDF 74,00€

ISBN 978-3-16-150697-0

fadengeheftete Broschur 74,00€
Veröffentlicht auf Englisch.

Michael B. Hundley untersucht das Priestertum, das entworfen wurde, um den Himmel auf Erden zu bewahren oder genauer gesagt, um die göttliche Gegenwart im Herzen der israelitischen Gemeinde zu festigen und zu erhalten. Dazu analysiert er die einzelnen Bestandteile des Priestertums. Er zeigt, wie die Priester, die als Schriftsteller tätig waren, das Wesen der göttlichen Gegenwart beschreiben, diese hervorlocken, uns auf seine Ankunft vorbereiten und uns durch den regelmäßigen

Gottesdienst an diese erinnern. Statt verschiedene priesterliche Rituale unabhängig von ihrem Kontext zu sehen, vergleicht Michael Hundley das Priestertum mit verschiedenen Systemen des Alten Orients (Ägypten, Mesopotamien, Hittite, SyrienPalästina). Mithilfe eines breitgefächerten Ansatzes entdeckt Hundley den Genius der priesterlichen Schriftsteller, der nicht in ihrer außerordentlichen Originalität, sondern in ihrer Fähigkeit besteht, Elemente aus den umgebenden Kulturen auszuwählen und sich diese anzueignen, um diese für ihre eigenen rhetorischen Zwecke zu nutzen.

Michael B. Hundley Born 1978; 2000 BA from Amherst College; 2010 Ph.D., University of Cambridge; currently Humboldt Postdoctoral Research Fellow at Ludwig-Maximilians-Universität Munich.

\section{Jetzt bestellen:}

https://mohrsiebeck.com/buch/keeping-heaven-on-earth-9783161511486?no_cache=1

order@mohrsiebeck.com

Telefon: +49 (0)7071-923-17

Telefax: $+49(0) 7071-51104$ 